\title{
ORGANIZAÇÃO DO CONHECIMENTO: TEORIAS SEMÂNTICAS COMO BASE PARA ESTUDO E REPRESENTAÇÃO DE CONCEITOS
}

\section{ORGANIZACIÓN DEL CONOCIMIENTO: TEORIAS SEMÁNTICAS COMO BASE PARA ESTUDIOS YREPRESENTACIÓN DE CONCEPTOS}

\author{
Lígia Café - ligia@cin.ufsc.br \\ Docente do Programa de Pós-graduação em \\ Ciência da Informação (UFSC) Doutora em Lingüística \\ Marisa Bräscher - marisa.brascher@gmail.com \\ Docente do Programa de Pós-graduação em Ciência da \\ Informação (UnB)Doutora em Ciência da Informação
}

\begin{abstract}
Resumo
Considera que a organização do conhecimento envolve a análise semântica e que a Ciência da Informação necessita de referencial teórico para os estudos que visam à representação conceitual de domínios do conhecimento. Apresenta alternativas teórico-metodológicas oriundas da Linguística e que partem de uma base semântica do estudo da língua: Teoria da Valência, Gramática de Casos, Gráficos Conceituais e a Teoria da Gramática Funcional. Prioriza as propostas teórico-metodológicas que tenham como princípio de interpretação a problemática semântica e que oferecem um caminho para pensar e refletir questões relacionadas aos diferentes aspectos semânticos no campo da Organização do Conhecimento.
\end{abstract}

\section{Palavras-chave}

Organização do Conhecimento. Teorias Semânticas. Análise Conceitual.

\section{INTRODUÇÃO}

A Organização do Conhecimento (OC), como campo de estudo, está fundamentada essencialmente em análises de cunho semântico. Relações semânticas são estabelecidas por meio da análise das características ou propriedades dos conceitos, 
as quais permitem identificar diferenças e semelhanças que evidenciam determinados tipos de relacionamentos, como afirma Bliss:

Na multiplicidade, diversidade e complexidade dos objetos naturais e suas relações, percebemos que coisas individuais e eventos diferem nas suas individualidades e características específicas, alguns são similares em certas características e relações; e por essas características de similaridade nós os relacionamos em classes e conceitos no processo de aprendizagem e de compreensão mental. (BLISS, 1952, p. 78)

A organização dos conceitos em classes é um processo arbitrário, no qual selecionamos os relacionamentos a serem apresentados, segundo as peculiaridades do domínio que pretendemos representar. Ao analisar um domínio, identificamos facetas e podemos agrupar os conceitos e relacioná-los de diferentes maneiras. Sowa (1984) destaca que:

[...] conceitos e percepções não podem formar modelos perfeitos de mundo, são abstrações que selecionam características importantes para determinada finalidade e que ignoram detalhes ou complexidades que são importantes apenas para determinados objetivos. (SOWA, 1984, p. 344)

Sendo assim, a mesma entidade pode ser caracterizada de diferentes maneiras, dependendo do domínio em questão e do tipo de sistema de organização do conhecimento que desejamos construir. A arbitrariedade da seleção dos agrupamentos e relacionamentos não pode ser vista, no entanto, como algo totalmente aleatório. Ela se deve aos aspectos que desejamos destacar numa determinada representação do conhecimento. Devemos atentar que, acima de tudo, como salienta Hodge (2000), "deve haver uma correspondência entre o sistema de organização do conhecimento e a realidade que ele pretende representar".

Além disso, tendo em vista que os estudos relacionados à organização do conhecimento tomam por base a realidade de um ou mais domínios, seus componentes (termos e relacionamentos semânticos) devem refletir o modelo comunicativo de determinada comunidade (incluindo suas ambigüidades e variações), sob pena de, descrevendo parcialmente uma dada realidade, provocar baixos índices na recuperação da informação. Isto porque a informação, representada pela articulação entre o termo e seu conceito, tem seu significado variável intrinsecamente ligado ao contexto de uso. As pesquisas na área de organização do conhecimento, portanto, devem procurar representar a terminologia de uma área de modo a descrevê-la nos planos linguístico, pragmático e funcional. 
Khoo e Na (2006) destacam que a pesquisa na área de Ciência da Informação concentrou-se por determinado período em conceitos e termos, mas que o interesse na identificação, processamento e gestão de relacionamentos vem aumentando, pela sua importância em diversas aplicações, sobretudo nas orientadas à recuperação da informação.

Hjorland (2007) ressalta que aspectos semânticos encontram-se presentes em todas as questões relacionadas à Ciência da Informação, mais particularmente, às orientadas para as pesquisas sobre organização do conhecimento. No entanto, segundo o mesmo autor, a semântica é um campo de estudo que sofre influências de distintas visões, por vezes conflitantes, sendo crucial questionar qual a mais apropriada para os objetivos da Ciência da Informação. Ainda sob o olhar desse autor, a $\mathrm{Cl}$ ainda não abordou os problemas semânticos de maneira sistemática, e os estudos sobre o tema encontram-se fragmentados e carecem de bases teóricas.

Nesse sentido, apresentamos neste artigo algumas alternativas teóricometodológicas oriundas da Linguística e que partem de uma base semântica do estudo da língua. São elas: Teoria da Valência, Gramática de Casos, Gráficos Conceituais e a Teoria da Gramática Funcional.

Considerando a Organização do Conhecimento como objeto de análise, o objetivo é priorizar as propostas teórico-metodológicas que tenham como princípio de interpretação a problemática semântica e oferecer um caminho para pensar e refletir questões relacionadas aos diferentes fenômenos existentes no campo da Organização do Conhecimento.

\section{TEORIA DE VALÊNCIA}

Essa teoria foi inicialmente proposta por Tesnière (1959), que considera a frase como um conjunto organizado formado por palavras e pelas conexões que se estabelecem entre elas. Segundo esse autor, a conexão é indispensável à expressão do pensamento. Sem a conexão, não saberíamos expressar nenhum pensamento contínuo e poderíamos enunciar uma sucessão de imagens e de idéias isoladas umas das outras sem ligação entre elas.

Tesnière (1959) compara a conexão que ocorre entre as palavras para formar uma frase com a combinação de substâncias químicas para formar um composto químico. Empresta, portanto, o conceito de valência da Química e define valência como "número 
de actantes que o verbo é capaz de reger" e actantes como "pessoas ou coisas que participam de alguma maneira no processo."(TESNIÈRE, 1959, p. 238).

Em sua teoria, Tesnière toma o verbo como elemento nuclear, já para Borba (1996, p. 20), valência possui uma conceituação mais genérica: "[...] propriedade que tem uma classe de elementos, de poder ligar-se com classes específicas de outros elementos sendo que esta mesma propriedade faz que esta classe se distingua de outras de mesmo nível sintagmático." Amplia, assim, o conceito de valência, abrangendo o regime dos nomes, adjetivos e de alguns advérbios. A valência constitui-se, então, no número de casas vazias (ou argumentos) implicadas pelo significado de um item lexical.

Para Borba (1996), uma gramática de valências procura estabelecer as relações de dependência entre categorias básicas que ocorrem num contexto - $A$ depende de $B, e$ a presença de $A$ pressupõe $B$. Toma como nuclear um elemento oracional e demonstra como os demais se dispõem em torno dele por meio de relações de dependência.

A dimensão sintática abrange os níveis das relações de dependência (propriedade e/ou função sintática ou morfossintática) e o tipo de condicionamento que identifica as condições de co-ocorrência no preenchimento das casas vazias por determinadas classes morfológicas. A dimensão semântica compreende o estudo das funções semânticas (ou papéis temáticos) preenchidos por essas classes. São três os elementos básicos de uma gramática de valências:

- argumento = casa vazia

- predicado $=$ núcleo oracional

- relação entre eles = símbolo $\mathbf{P ( A )}$

Borba (1996) utiliza o termo valência em três níveis:

a) Valência quantitativa, valência lógica ou lógico-semântica - nível geral e abstrato que diz respeito ao número de argumentos que um predicado pode ter. De acordo com este ponto de vista, o predicado pode ser:
avalente
$P(0)$ - nevar, chover, trovejar
monovalente
$P(A)$ - dançar, brincar, chorar
divalente
$P(A 1, A 2)$ - encontrar, olhar, pender
trivalente
$P(A 1, A 2, A 3)$ - dar, roubar, ligar, pendurar
tetravalente
$P(A 1, A 2, A 3, A 4)$ - transferir, traduzir, transpor 
b) Valência qualitativa, valência sintática ou morfossintática - nível que trata das características dos actantes, do preenchimento das casas vazias por determinadas classes com determinadas propriedades morfológicas. Atua no nível da função sintática, de propriedade sintática (pronominalização, ordem, etc.), das classes que preenchem os argumentos, das propriedades morfossintáticas dos itens que preenchem os argumentos.

c) Valência semântica - nível que se serve da observação das regularidades ou compatibilidades das unidades que operam nas seqüências. Diz respeito às características categoriais, às funções temáticas (=papéis) como agente, causativo, beneficiário experimentador, etc., e às restrições selecionais que determinam classes/subclasses de itens que podem preenchem os argumentos de determinado predicado.

Uma gramática de valências deve ser capaz de representar a dependência e a regência que se estabelecem entre o predicado e o argumento. Segundo Borba (1996), pode-se resumir assim as características deste tipo de gramática:

a) É uma gramática da frase, que toma o verbo como ponto de partida e analisa os constituintes oracionais seguindo uma marcha descendente, i.é, dos constituintes maiores para os menores, primeiro o constituinte da frase, depois os constituintes dos constituintes da frase.

b) Utiliza uma classificação funcional (e não categorial) que permite perceber a função sintática na diversidade de realizações morfológicas. Distingue constituintes de função primária, que são obrigatórios por realizarem os argumentos, e os constituintes com função secundária que são facultativos por serem oracionais.

Borba defende a idéia de que a análise valencial não se limite apenas a identificar (ou construir) matrizes ou a descrever a estrutura externa dos constituintes, mas que esta deve, também, determinar as relações sintático-semânticas ou temáticas (funções ou papéis temáticos) que fazem parte da estrutura conceitual dos itens léxicos. Estas relações são expressas por meio de uma gramática de casos.

\section{GRAMÁTICA DE CASOS}

Fillmore (1968) desenvolveu um modelo de gramática cujo traço característico é o fato de considerar que a sentença, em sua estrutura básica, é formada por um verbo e um 
ou mais sintagmas nominais, cada um deles associado ao verbo por uma relação de caso particular. $\mathrm{O}$ autor coloca em evidência as relações semânticas que existem entre o verbo e os sintagmas nominais, a partir da análise de frases como:

A porta abriu.

João abriu a porta.

O vento abriu a porta.

João abriu a porta com a chave.

Nestas frases, o sintagma nominal a porta, João e o vento têm diferentes relações semânticas com o verbo. Fillmore demonstra que as noções de sujeito e objeto não são, portanto, as mais profundas possíveis (do ponto de vista do significado), representam apenas um nível intermediário. (TEIXEIRA, 1987)

Para representar as relações que se estabelecem em nível subjacente, Fillmore propõe um conjunto de casos semânticos, considerando caso como "um conjunto de conceitos universais presumivelmente inatos, que identificam certos tipos de julgamentos que os seres humanos são capazes de fazer sobre os eventos que ocorrem ao seu redor, como: quem fez isto, a quem aconteceu isto, e o que sofreu mudança." (FILLMORE, 1968, p. 24).

O primeiro conjunto de casos proposto por Fillmore (1998) inclui agentivo, instrumental, dativo, factitivo, locativo, objetivo. O número e tipo de casos variam de autor para autor. Mesmo Fillmore em seus trabalhos apresenta diferentes propostas de casos. Os casos são utilizados para atribuir esquemas casuais aos verbos, para indicar o tipo de ligação que seus argumentos possuem com ele. (TEIXEIRA, 1987)

Borba (1996) utiliza os princípios da gramática de casos de Fillmore para estabelecer correspondências entre constituintes conceituais e constituintes sintáticos. No exemplo abaixo ${ }^{1}$ pode ser observado que, a cada constituinte frasal maior portador de conteúdo (sintagma nominal, sintagma verbal...) corresponde uma categoria conceitual.

Estrutura sintática:

$\mathrm{O}[\mathrm{SN}$ - João] + [SV - correu $]+[$ Sprep - para o quarto $]$

Estrutura conceitual:

Ação [correr] + objeto [João] + direção [quarto]

${ }_{1}^{1}$ Relação entre a estrutura sintática e estrutura conceitual, extraído de Borba (1996, p. 28) 
Na estrutura sintática, os constituintes desempenham funções, que estão sempre vinculadas à estrutura. Uma função não está diretamente condicionada à natureza de um elemento: um mesmo elemento pode ter funções diferentes, como, por exemplo, um nome que pode funcionar como sujeito ou complemento. Da mesma maneira, dois elementos de classes diferentes podem ter a mesma função: nome, adjetivo ou verbo podem funcionar como núcleo de predicado.

$\mathrm{Na}$ estrutura conceitual, os elementos são classificados de acordo com categorias conceituais primitivas previamente definidas, como, por exemplo: entidade, ação, evento, objeto, etc. Neste nível de análise, os elementos desempenham papéis temáticos, que, por sua vez, também se constituem em configurações estruturais.

As relações que se estabelecem entre os elementos neste nível são chamadas relações temáticas e são representadas por uma gramática de casos, entendendo-se caso como:

a) relação sintático-semântica entre um predicado e um argumento

b) resultado de uma relação sintática que tem uma conseqüência semântica

c) categoria subjacente, isto é, propriedade gramatical universal que não se confunde com funções superficiais do tipo sujeito, objeto direto, objeto indireto tais como vêm tratados na gramática tradicional. (BORBA, 1996, p. 14)

$\mathrm{O}$ nome de cada caso refere-se ao valor semântico que expressa:agentivo $=0$ que age ou faz; experimentador $=0$ que experimenta; beneficiário $=0$ que se beneficia, $\mathrm{e}$ assim por diante. Esse valor semântico não está ligado ao léxico em si, mas a uma relação, ou seja, o semântico é uma conseqüência do sintático. Cavalo só é agentivo quando está relacionado com outro elemento da categoria conceitual ação que funcione como núcleo do predicado.

\section{GRÁFICOS CONCEITUAIS}

A teoria dos gráficos conceituais (GCs) começou a ser desenvolvida por Sowa em 1968, quando escreveu um trabalho de final de curso para Minsky. Neste trabalho, Sowa aplicou a idéia de fluxogramas para criar um modelo de representação de conhecimento em IA que se utilizam de caixas e círculos para gerar gráficos conceituais.

$\mathrm{Na}$ década de 70 , Sowa inicia um trabalho sério de pesquisa sobre gráficos conceituais como linguagem de representação do conhecimento no Systems Research Institute da IBM. O resultado deste trabalho é publicado, em 1976, no IBM Journal of Research and Development. Oito anos após, Sowa publica seu livro Conceptual Structures (SOWA, 1984), apresentando a teoria de GCs como hoje é conhecida. 
Com base no suposto de que conhecimento em Inteligência Artificial "...é a habilidade de formar um modelo mental que represente adequadamente as coisas assim como as ações que podem ser por elas ou sobre elas executadas", Sowa (1984) propõe seu modelo de representação do conhecimento denominado gráficos conceituais.

Os GCs formam uma linguagem de representação do conhecimento e são constituídos por gráficos que possuem dois tipos de nós:

a) os conceitos, representados por caixas CONCEITO ou por colchetes [CONCEITO], correspondem a conteúdos de pensamento; representam entidades, ações ou estados que possam ser descritos em termos de linguagem,

b) as relações, representadas por círculos com uma flecha de entrada e outra de saída $\rightarrow$ RELAÇÃO $\rightarrow$ ou entre parênteses $\rightarrow$ (RELAÇÃO) $\rightarrow$, simbolizam as ligações existentes entre os conceitos e demonstram os papéis que cada entidade desenrola. (NOGIER, 1991; SOWA, 1984).

Para Sowa (1984, p. 20), "os gráficos conceituais formam uma base semântica da linguagem natural e representam modelos do mundo real ou de um mundo possível." No esquema da figura 1 Sowa demonstra como funciona o mecanismo implícito no triângulo do conceito, com os GCs servindo de ligação entre o referente e o significante, onde:

a) «as regras de sintaxe mapeam gráficos para sentenças em LN e mapeam sentenças para gráficos.

b) os arcos dos gráficos correspondem à função da palavra e a casos relacionais da LN.

c) os nós dos gráficos são conceitos intensionais de indivíduos que devem existir no mundo real ou em algum mundo hipotético.» (SOWA, 1984, p. 20) 


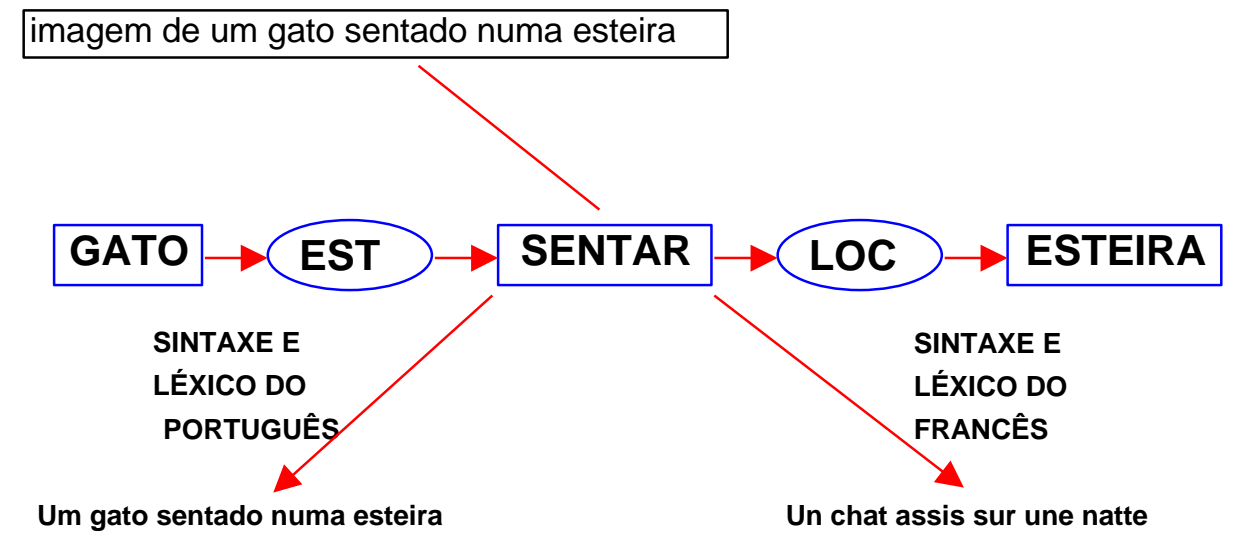

Figura 1 - Percepção, conceito e linguagem ${ }^{2}$

Os GCs são definidos por Sowa (1984) como uma linguagem universal e independente, no nível da estrutura profunda. Essa afirmação pode ser verificada na figura 1, em que o mesmo gráfico, gerado a partir de um processo de percepção, serve de representação para as frases expressas nas duas línguas - português e francês.

De acordo com Sowa (1984), os GCs são:

a) finitos: qualquer gráfico possui apenas um número finito de conceitos e relações conceituais;

b) conectados: duas partes que não estão conectadas são consideradas simplesmente dois gráficos conceituais; $\mathrm{e}$

c) bipartites: dois tipos de nós são utilizados - um para conceitos e outro para relações e todo arco liga um nó de um tipo a um nó de outro tipo.

Apesar de alguns autores usarem os termos rede semântica e gráfico conceitual quase como sinônimos, Sowa (1984) faz uma distinção entre esses dois tipos de representação. Para o autor, um GC representa uma única proposição, ao passo que uma rede semântica é mais ampla e inclui um conjunto de relações para cada tipo de conceito.

\subsection{Conceitos nos GCs}

Nos gráficos conceituais, um conceito é um objeto que possui um tipo e um referente que especifica exatamente que espécie do tipo precedente o conceito representa. Para Sowa (1984), a distinção entre tipo e conceito é a mesma que Peirce faz entre tipos e tokens: "[...] a palavra gato é um tipo, e cada realização (utterance) de gato é um novo token. De maneira similar, cada ocorrência de um conceito é um token separado, mas os tokens são classificados por um conjunto T de tipos básicos."

${ }^{2}$ Figura adaptada de Sowa (1984, p.39). 
O tipo do conceito não é necessariamente muito distante (do ponto de vista semântico) do conceito representado. Por exemplo, o tipo do conceito GATO é GATO e não MAMÍFERO, apesar de gato ter como hiperônimo mamífero. Esta relação de hiperonímia encontra-se representada por uma rede, chamada treillis de conceitos, na qual é estabelecida a hierarquia entre tipos. A relação representada nessa hierarquia é uma relação de ordem de grandeza que se estabelece entre tipos de conceitos e não entre conceitos individuais.

Existem, assim, diversas famílias de conceitos, isto é, conjuntos de conceitos que têm o mesmo hiperônimo. Esses conceitos são ditos do mesmo tipo. Tomando-se como exemplo o tipo FRUTA ${ }^{3}$, pode-se dizer que laranja, pêra e banana são do tipo FRUTA fruta é um hiperônimo de laranja, pêra e banana.

A hierarquia de tipos é um ordenamento parcial definido a partir de um conjunto de etiquetas de tipo. O símbolo $\leq$ determina a ordem hierárquica. Os termos subtipo e supertipo são utilizados para designar a posição dos conceitos na hierarquia, como abaixo:

Se $\mathrm{X}<\mathrm{Y}$, então:

$X$ é um subtipo de $Y, e$

$Y$ é um supertipo de $X$.

Se $X \leq Y$ e $X \leq Z$, então:

$X$ é um subtipo comum de $Y$ e $Z$.

Se $X \geq Y$ e $X \geq Z$, então:

$X$ é um supertipo comum de $Y$ e $Z$.

Para transformar a hierarquia de tipos num treillis, Sowa (1984) introduziu duas etiquetas de tipo como topo e base da cadeia hierárquica: o tipo universal $\mathrm{T}$, que é o supertipo de todos os outros tipos e o tipo absurdo $\perp$ que é o subtipo de todos os outros tipos. $O$ treillis de conceitos forma, assim, um gráfico como o da figura 2.

Figura 2 - Treillis de conceitos. ${ }^{4}$

\footnotetext{
${ }^{3} \mathrm{Na}$ teoria dos GCs, as etiquetas de tipo são escritas em letras maiúsculas para diferenciá-las do conceito em si mesmo.

${ }^{4}$ Figura adaptada de Nogier (1991)
} 


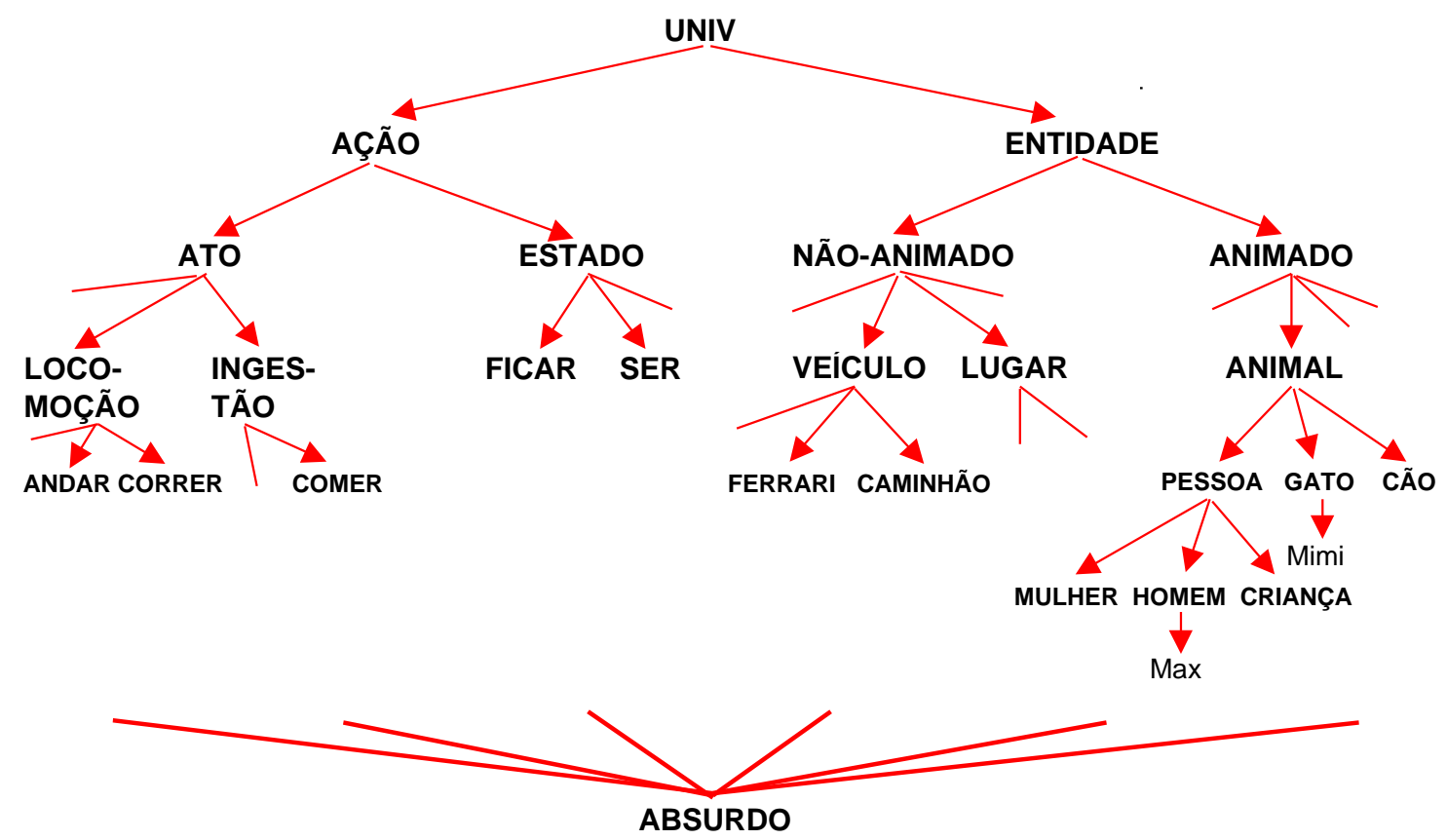

$\mathrm{Na}$ hierarquia de tipos, assim como em outras estruturas hierárquicas gênero/espécie baseadas em Aristóteles, os subtipos herdam as propriedades de seus supertipos. Um treillis de conceitos deve ter supertipos e subtipos comuns. Essa característica fica mais evidente quando tipos intermediários são introduzidos na hierarquia. Assim, por exemplo, se os tipos VERTEBRADO, MAMÍFERO e CARNÍVORO forem introduzidos no treillis da figura 2, GATO e CACHORRO passam a ter o supertipo mínimo comum CARNíVORO.

Para indicar os tipos de conceitos de forma linear, utiliza-se a seguinte notação:

$[<$ tipo $>:<$ referente>]

Ex.: [INSTITUIÇÃO : 'Petrobrás']

O referente pode não estar indicado, quando se trata de um conceito genérico:

[GATO: *] ou [GATO] $\rightarrow$ um gato

Qualquer conceito pode ser representado por meio de um gráfico conceitual, a complexidade do gráfico dependerá do nível de complexidade da realidade que se deseja representar. 
As relações conceituais definem o papel de cada conceito num GC. São as ligações que se estabelecem entre os conceitos do gráfico. Podem ter um número qualquer de arcos, sendo que a relação mais comum é díade ${ }^{5}$.

A representação em diagramas não é fácil de ser construída quando se estabelecem várias relações entre os conceitos do GC. Dessa forma, Sowa (1984) propõe uma notação linear que substitui os diagramas, escolhendo como cabeça o conceito ao qual se ligam maior número de arcos. O gráfico conceitual

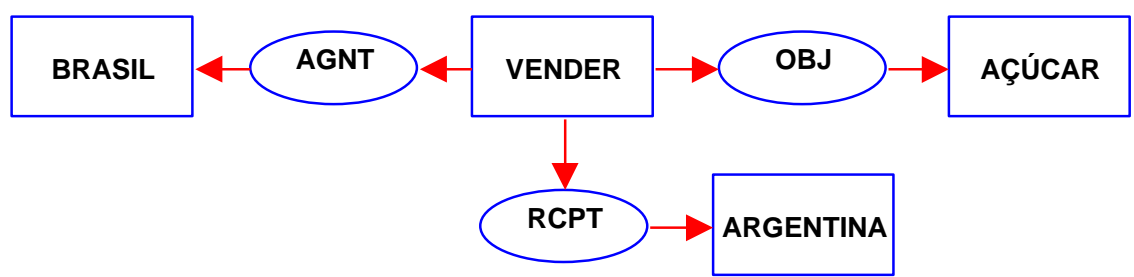

é representado linearmente assim:

[VENDER]-

$$
\begin{aligned}
& (\text { AGNT }) \rightarrow \text { [BRASIL] } \\
& (\text { OBJ }) \rightarrow[\text { AÇUCAR] } \\
& (\text { RCPT }) \rightarrow \text { [ARGENTINA] }
\end{aligned}
$$

Os GCs devem ser lidos de acordo com o sentido das flechas. No exemplo dado, lê-se: VENDER tem por agente BRASIL, por objeto AÇÚCAR e por receptor ARGENTINA.

Esse tipo de representação segue uma sintaxe própria, como o emprego do hifem após a caixa do conceito VENDER, para indicar que as relações que se estabelecem com este conceito estão listadas nas linhas subseqüentes. A sintaxe completa utilizada nessa notação é descrita por Sowa (1984) no apêndice A6 de seu livro.

As duas notações - a linear e a em gráfico - são exatamente equivalentes e podem, como afirma Sowa (1993) ser traduzidas automaticamente para outras formas de lógica ou de representação do conhecimento. Sowa demonstra como os GCs são, ainda, passíveis de transformação em fórmula da lógica de predicados do primeiro grau.

Os GCs constituem-se num formalismo de representação do conhecimento baseado na lógica. Há grande interesse na área pelo desenvolvimento de experimentos em diferentes domínios, como ontologias, estruturas de dados e motores de inferência.

\footnotetext{
${ }^{5}$ Segundo o número de arcos, as relações conceituais são denominadas por Sowa como monoades (um arco) ; díades (dois arcos) ; tríades (três arcos)...n-ades (n arcos)
} 
Todos estes sistemas exploram a flexibilidade dos GCs na tradução de um formalismo teórico numa aplicação práticas.

A abordagem sintático-semântica proposta na Teoria de Valência, Gramática de Casos e Gráficos Conceituais foi adotada em pesquisas anteriores relatadas em Bräscher (1999) e Bräscher (2002). Esses estudos orientam-se ao processamento automático da linguagem natural (PLN) para fins de recuperação da informação. A disponibilidade de informação textual em meio digital apresenta-se como um contexto relevante para aplicações de PLN com base em abordagens orientadas ao estudo sintático-semântico da linguagem.

\section{TEORIA DA GRAMÁTICA FUNCIONAL DE SIMON DIK}

A terminologia de uma linguagem de especialidade serve para nomear os conceitos adotados na comunicação de experiências entre especialistas de uma área do conhecimento. Neste contexto, a língua é interpretada como um instrumento de interação social e o termo é considerado como o meio capital utilizado neste processo. Os conceitos a serem transmitidos podem ser de natureza simples ou complexa. Nos textos especializados, as unidades terminológicas complexas (UTC) são frequentemente utilizadas para representar conceitos complexos, ou seja, conceitos que possuem uma acumulação de traços semânticos que thes conferem um sentido preciso. Essas UTC armazenam uma carga de informação semântica, sintática e pragmática que determina o comportamento linguístico de uma área do conhecimento. Com base na Teoria da Gramática Funcional de Simon Dik, apresenta-se a seguir uma interpretação, de cunho funcionalista, dessas informações, segundo seu papel na comunicação especializada.

Uma análise do ponto de vista funcional tem por fundamento a concepção da língua como:

a) objeto de estudo dinâmico e variável ;

b) sistema que possui elementos nucleares e periféricos que se combinam por um processo predicativo;

c) sistema que percebe as regras e os princípios da gramática muito mais como tendências surgidas no seio do uso da língua do que como modelos absolutos (NEVES, 1997)

As linguagens de especialidade, consideradas como parte da língua geral, podem e devem ser estudadas seguindo essa mesma concepção. A perspectiva de base funcional é justificada por acreditarmos que as UTC são unidades formadas de uma base seguida de predicações nucleares ou estendidas, cujos componentes veiculam funções 
semântica, sintáticas e pragmáticas definidas segundo relações estabelecidas entre eles. Uma UTC obedece, necessariamente, a um processo de incidência de predicações sucessivas. Esse processo reflete o uso da terminologia na situação de comunicação onde é empregada.

A aplicabilidade da Gramática Funcional de Simon Dik para o estudo das UTC é comprovada pela análise, do ponto de vista desta teoria, da UTC indução floral in vitro, da área da Biotecnologia de Plantas, mostrada no final desta sessão. Demonstra-se assim que teorias funcionalistas concebidas para o estudo da língua geral podem ser adaptadas aos propósitos de estudos terminológicos e, consequentemente, tem seu papel no exame dos fenômenos das línguas de especialidade que afetam a organização do conhecimento.

A Teoria da Gramática Funcional tem por fundamento a Linguística Funcional, cujas origens trazem a idéia inovadora da linguística saussureana sobre o papel da língua como instrumento de comunicação. Mesmo sabendo que Saussure não se caracteriza como um funcionalista, o princípio de base saussureana é retomado por alguns representantes da Escola Funcionalista. Desta forma, "[...] consideram o estudo da língua como a pesquisa das funções exercidas pelos elementos, classes e mecanismos que nela intervem" (DUCROT; TODOROV, 1972, p. 42).

Segundo Lyons (1981), a Linguística Funcional européia tem seu início com a criação, em 1926, da Escola de Praga. A partir de então, diversas correntes surgiram como reflexo de abordagens diferenciadas sobre a concepção funcionalista da língua. No entanto, podemos dizer que elas têm em comum a verificação, a descrição e a análise das múltiplas maneiras de proceder da língua para atingir o objetivo principal de comunicação.

Do ponto de vista metodológico, o pesquisador funcionalista recupera um item lexical considerando seu uso e, consequentemente, o contexto em que a unidade está inserida. $O$ funcionalista busca 0 referente e a motivação funcional das estruturas linguísticas no discurso.

A teoria da gramática das línguas é claramente uma das áreas da Lingüística que tem absorvido os resultados do pensamento funcionalista. No contexto europeu, dois modelos se destacam: a Gramática Funcional Sistêmica de Halliday (DAVIDSE, 1987, p. 39 - 79) e a Gramática Funcional de Simon Dik (1978; 1980; 1983; 1987; 1989). Os dois autores se enquadram no chamado funcionalismo moderado. Neste artigo, destacamos a Teoria de Simon Dik, um representante do grupo da Holanda, que enfatiza o caráter 
funcional e dinâmico da língua. O primeiro registro de sua teoria encontra-se no livro intitulado Funcional Grammar, publicado em 1978. Posteriormente, esta obra sofreu adaptação que foram apresentadas em 1989 na publicação The Theory of Funcional Grammar.

A Gramática Funcional analisa a língua com base em quatro princípios: da funcionalidade, da adequação tipológica, da adequação pragmática e da adequação psicológica.

Quanto a princípio da funcionalidade, a língua é vista como um instrumento de interação social cuja função é comunicar. No seio do papel comunicativo está a natureza ideológica da língua. Ao fazermos um paralelo entre a língua geral e a de especialidade, pode-se constatar que no segundo caso o princípio de funcionalidade está vinculado as características da comunicação entre especialista e, portanto, carrega sua natureza ideológica.

Em relação ao princípio da adequação tipológica, Dik constata que a teoria é capaz de produzir gramáticas para todas as línguas, considerando suas similaridades e diferenças. Esta peculiaridade da teoria torna viável sua adaptação ao estudo das linguagens de especialidades.

A adequação pragmática observa as estruturas lingüísticas em situação discursiva na qual se supõe a existência de um emissor, cuja finalidade é produzir uma reação deliberada no receptor. A intenção do emissor é provocar uma reação capaz ou não de mudar o estado de conhecimento do receptor. O objeto lingüístico, cercado de outras expressões, obedece a parâmetros reguladores segundo a finalidade comunicativa. A adequação pragmática é de grande relevância para os estudos voltados à dimensão comunicativa da terminologia de uma linguagem de especialidade.

Por fim, no princípio da adequação psicológica, Dik considera os modelos psicológicos de competência e comportamentos lingüísticos dos seres humanos que produzem as expressões lingüísticas. Ressaltamos a importância deste princípio na interpretação dos neologismos terminológicos, prática freqüente em áreas do conhecimento de grande produção científica e tecnológica. A criação neológica, segundo Sager (1990), sofre inluência das características da area do conhecimento a que pretence.

Do ponto de vista metodológico, a Gramática funcional oferece um modelo para a construção de predicados abstratos baseado na análise de estruturas lingüísticas 
presentes no léxico de uma língua. Trata-se do método de predicação para descrição lingüística. Nele todos os elementos de uma língua são analisados por meio da predicação que revela as propriedades funcionais e categoriais de cada constituinte da expressão lingüística. Para a análise de UTC, este modelo de predicação é adequado, pois os termos utilizados nas linguagens de especialidade carregam consigo não só aspectos funcionais e categoriais de cada item lexical, mas também expressam a relação entre seus componentes com a finalidade de comunicar as idéias do especialista. Assim, apesar do modelo de predicação proposto por Simon Dik tenha objetivado o estudo da língua geral, acreditamos ser ele capaz de ser adaptado aos estudos em terminologia, em especial as relações internas das UTC. É isto que apresentamos a seguir.

Dik definiu o modelo de predicação para análise da língua geral. Este modelo é composto de predicados e termos.

Os predicados são expressões que designam propriedades (por exemplo, as categorias gramaticais) ou relações entre as entidades (por exemplo, as funções semânticas) (DIK, 1983, p. 10). A predicação é uma aplicação dos predicados a um número de termos. Estes termos podem ser de bases ou termos derivados (DIK, 1981, p. 4 e 6). O conjunto de predicados de base é composto por todas as estruturas predicativas de uma língua, enquanto os predicados derivados são uma aplicação das estruturas ao léxico de uma língua. Dik adota algumas considerações básicas sobre o que ele entende por predicado. Citamos quatro delas:

a) todos os elementos lexicais de uma língua são passíveis de análise como predicados;

b) podem existir diferentes tipos de predicados (verbais, adjetivais ou nominais);

c) todos os predicados são semanticamente interpretados como designadores de propriedades ou relações;

d) os predicados são analisados por estruturas de predicados que especificam suas propriedades semânticas e sintáticas (1989, p. 54).

O modelo torna-se uma predicação quando os termos são aplicados a estrutura predicativa (DIK, 1981, p. 7). Dik apresenta essa estrutura da seguinte forma:

Figura 3- Estrutura geral da predicação 


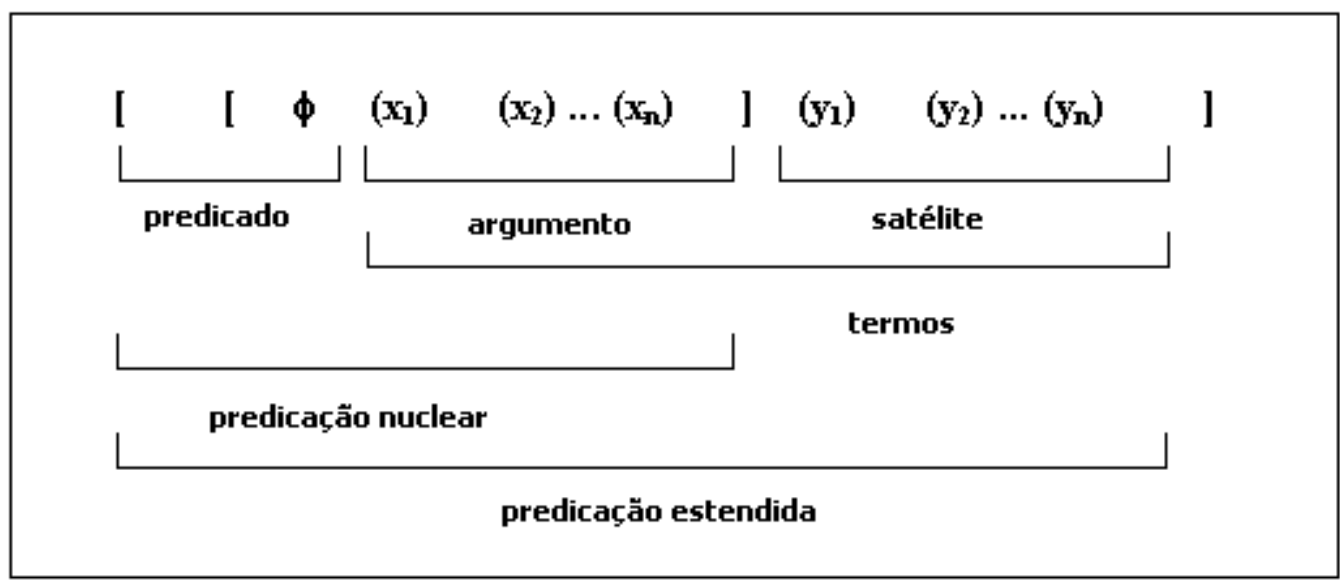

Cada etiqueta do modelo significa:

a) predicado: centro da expressão lingüística. Com base neste elemento, podemos descrever as predicações nucleares e estendidas. A predicação comporta toda a informação necessária para a descrição da predicação.

b) argumento: elemento exigido pela semântica da predicação. Fundamental para a construção da predicação nuclear, matém uma relação direta com o predicado e ocupa uma posição importante na predicação.

c) satélite: tem função periférica na expressão linguística. Complementa a informação sobre o estado de coisas6 da predicação nuclear e mantém uma relação com essa predicação como um todo.

d) termo: pode ocupar uma posição de argumento ou de satélite e se refere a uma entidade da realidade.

e) predicação_nuclear: é a aplicação de um predicado a um número de termos que funciona como argumento desse predicado. É formada pelo predicado e seus argumentos.

f) predicação_estendida: é formada pela predicação nuclear e os satélites.

${ }^{6}$ Segundo Dik, o estado de coisas "é adotado no sentido amplo de 'concepção de alguma coisa que pode estar em algum lugar'”" (1989, p. 89) 
Ao adaptar o modelo de predicação ao estudo das expressões terminológicas, as UTC são definidas como unidades formadas por uma base, argumentos e satélites. A base e os argumentos formam a predicação nuclear. A junção dos satélites a predicação nuclear forma a predicação estendida. São estes dois tipos de predicação que constituem a estrutura geral da predicação em terminologia, ilustrada na figura a seguir.

Figura 4 - Modelo de predicação de UTC

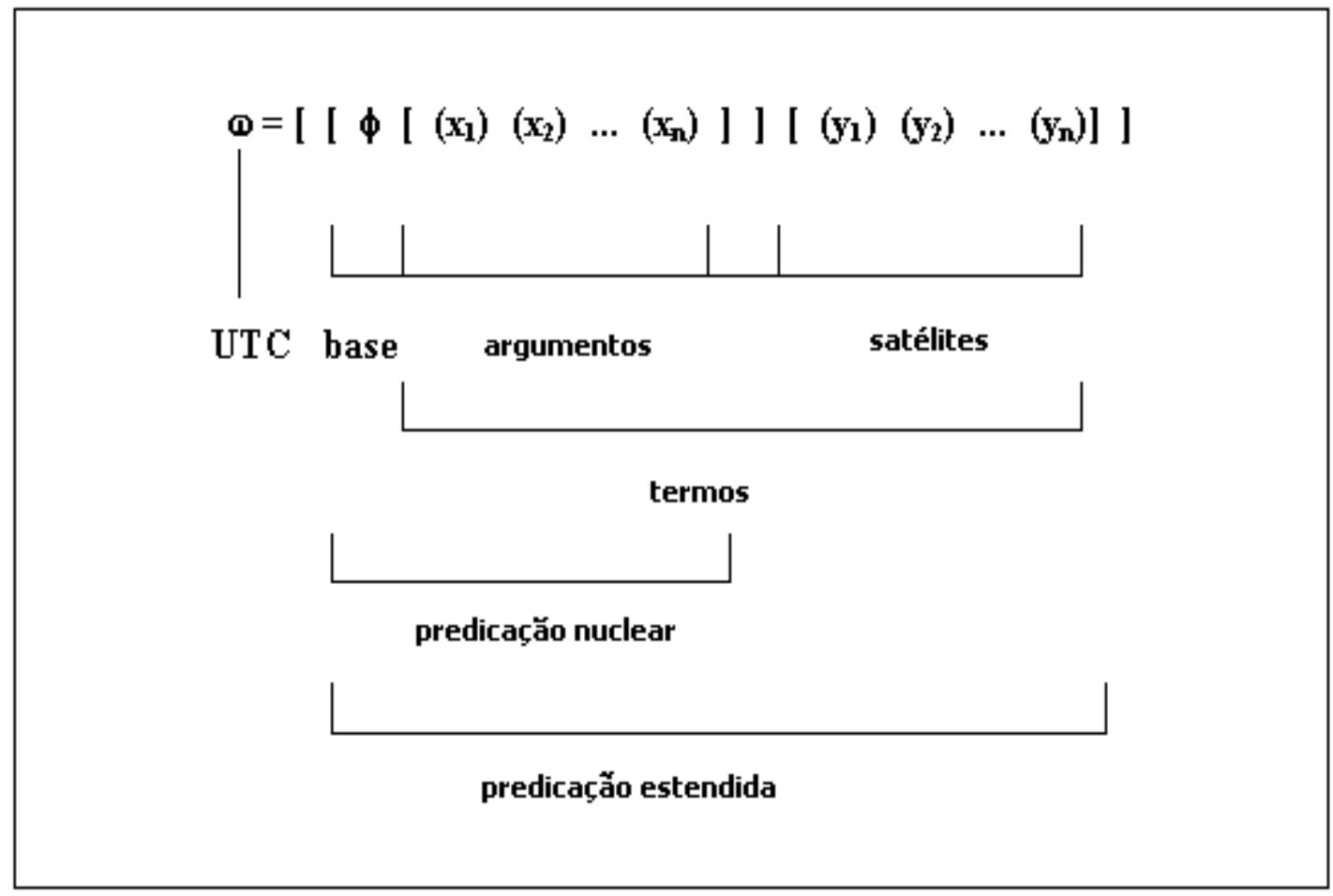

Onde:

$$
\begin{aligned}
& \omega=\text { UTC } \\
& \phi=\text { base } \\
& \mathrm{x}=\text { argumento } \\
& \mathrm{y}=\text { satélite }
\end{aligned}
$$

Os índices 1, 2 e $n$ indicam a ordem dos argumentos e dos satélites na UTC. Os colchetes são utilizados para circundar os conjuntos e subconjuntos de relações estabelecidas entre os elementos da UTC. Essas relações podem existir no interior da predicação nuclear ou da predicação estendida. Pode-se igualmente encontrar relações dentro de um conjunto de argumentos. Nesse caso, utilizamos a barra oblíqua (/) para mostrar a hierarquia relacional entre os argumentos. Este signo gráfico é utilizado principalmente para marcar a expansão de um argumento, ou seja, no caso de um argumento ser modificado ou especificado por outro argumento. A determinação de uma 
regra de formação para uma UTC é fundamentada em um conjunto de interpretações de cunho funcionalista.

A aplicação do modelo a determinada UTC resulta em uma regra de formação. Esta regra representa sintetiza a interpretação das relações funcionais estabelecidas entre os componentes da UTC. Na Gramática Funcional, com base na perceptiva semântica, são propostos os meios para identificar os componentes da expressão e determinar suas funções semânticas, sintáticas e pragmáticas e assim definir a regra de formação da UTC.

Dik define estas funções como:

a) funções semânticas: especificam os papéis que cada referente, representado por termos, tem em relação ao estado de coisas: agente, meta, recipiente, beneficiário etc.

b) funções sintáticas: especificam a prespectiva segundo a qual o estado de coisas é apresentado na expressão linguística: sujeito e objeto.

c) funções semânticas: especificam o estatuto informacional de cada elemento de uma predicação: tema, tópico, foco etc. (BRITO, 1994, p. 82).

Para determinar as funções semânticas, Dik (1989, p. 89-109), fixa os seguintes parâmetros:

Figura 5 - Parâmetros para o estabelecimento das funções semânticas

$\begin{array}{ll} \pm \text { Dinâmico } & {[ \pm \text { din }]} \\ \pm \text { Télico } & {[ \pm \text { tel }]} \\ \pm \text { Momentâneo } & {[ \pm \text { mon }]} \\ \pm \text { Controlado } & {[ \pm \text { con }]} \\ \pm \text { Experiência } & {[ \pm \text { exp }]}\end{array}$

Á título de ilustração, escolhemos o parâmetro dinâmico para exemplificar sua aplicabilidade. Nesse caso, existe uma noção de mudança que pode ser positiva ou negativa. Quando negativa [-din], não existe mudança, o que Dik denomina situação. Inversamente, no que diz respeito ao traço [+din], existe mudança, e Dik nomeia como evento. Os exemplos retirados de Dik (1989, p. 91) ilustram esses traços:

a) João estava sentado na cadeira e seu pai. [- din]

b) João abriu a porta [+ din]

No primeiro exemplo, temos o que Dik determina como situação, enquanto que no segundo exemplo trata-se de um evento. 
Na figura a seguir proposta do Dik (1989, p. 98), é possível verificar estes parâmetros aplicados a determinadas funções semânticas.

Figura 6 - Esquema de inter-relações entre os parâmetros

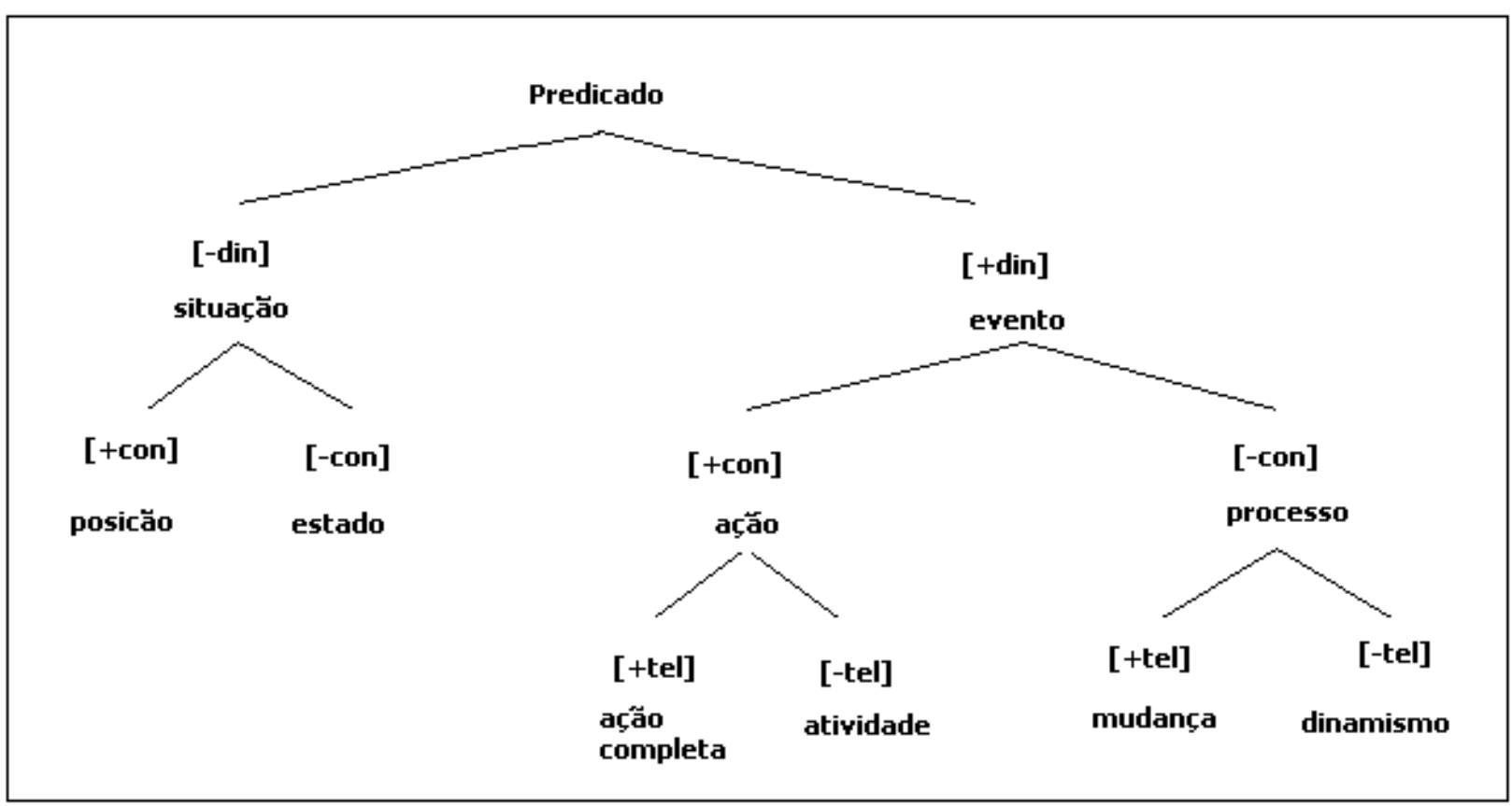

Esse esquema mostra, por exemplo, que uma ação é um evento mais controlado, enquanto um processo se caracteriza por ser um evento menos controlado. Esse tipo de distinção é útil quando da atribuição das funções semânticas dos diversos elementos de uma expressão lingüística.

No que se refere à função sintática, a Gramática Funcional a interpreta partindo de uma perspectiva semântica, o que difere profundamente do que é definido nas gramáticas tradicionais. Para Dik, a função de sujeito, por exemplo, é o elemento de partida da análise semântica. Sujeito e objeto definem "diferentes perspectivas sobre o estado de coisas designado pela predicação" (DIK, 1989, p. 25).

Em relação à função pragmática, na Teoria da Gramática Funcional, Dik ressalta que elas têm a função de fornecer o "status informacional dos constituintes em relação ao conjunto comunicativo maior no qual estão inseridas" (DIK, 1989, p. 264). Sua análise resulta de uma situação comunicativa entre emissor e receptor. A Gramática Funcional define dois tipos de parâmetros para definir as funções pragmáticas:

a) Tópico: usado para determinar o que se está falando.

b) Foco: usado para determinar do que se fala sobre o tópico. 
Ao aplicarmos o modelo de predicação, apresentado na figura 4, à UTC indução clonal in vitro, termo da área da Biotecnologia de Plantas, obtemos a seguinte regra: $\omega=[$ [ $\phi[\mathrm{x} 1]][\mathrm{y} 1]]$.

onde:

$\omega(\mathrm{UTC})=$ indução floral in vitro

$\phi$ (base da UTC) $=$ indução

$x_{1}$ (argumento) $=$ floral

$\mathrm{y}_{1}$ (satélite) $=$ in vitro

De forma mais detalhada ilustramos na figura 5 a aplicação do modelo de predicação ao estudo da UTC.

Figura 7 - Exemplo de análise funcional da UTC indução floral in vitro

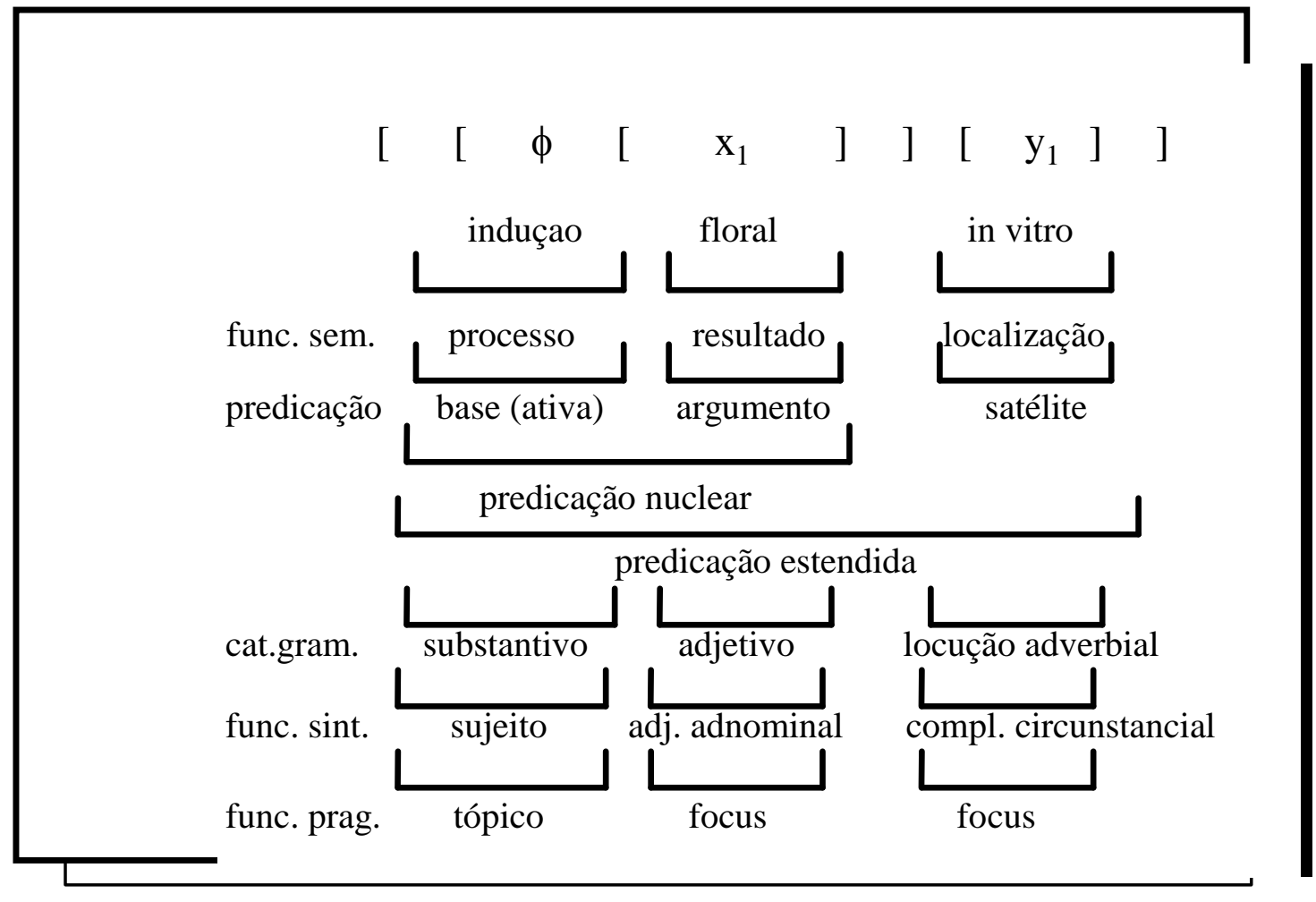

A análise desta figura deve ser feita iniciando pela perspectiva semântica, ou melhor, identificamos a função semântica de cada componente da UTC. Assim, indução representa o papel de processo; floral, o papel de resultado; in vitro, de localização. Essa interpretação é fundamentada no conhecimento de que indução constitui um processo que resulta em floração e é feita in vitro (em laboratório). Com base nesses dados, podemos aplicar a análise da predicação e assim definir ser indução a base do segmento, 
pois, por meio dela, podemos determinar o papel semântico dos outros componentes da UTC. Além disso, a base é dita ativa, pois se trata de um substantivo derivado de um verbo.

À direita de indução, encontra-se o elemento floral. Considera-se esse componente um argumento por dois motivos:

a) mantém relação direta com a base;

b) consiste em elemento fundamental exigido pela semântica da predicação. Sem ele, a informação seria incompleta.

O elemento seguinte a ser analisado é in vitro. Esse é classificado como satélite, pois mantém relação com todo o conjunto de elementos à esquerda do segmento. Em outras palavras, o satélite in vitro relaciona-se com a predicação nuclear formada pela base indução e o argumento floral. O conjunto da predicação nuclear mais o satélite forma a predicação estendida.

Esta interpretação nos leva a determinar a regra de formação desta UTC, qual seja $[[\varnothing[\mathrm{x} 1]][\mathrm{y} 1]]$.

Prosseguindo a análise, determinamos para cada componente da UTC a sua categoria gramatical, função sintática e função pragmática. No concernente às categorias gramaticais, a UTC indução floral in vitro é formada de Subst. + Adj. + Loc. Adv. Quanto às funções sintáticas, indução representa o sujeito da UTC. Esta função é atribuída a todos os elementos de uma UTC considerados como ponto de partida para a análise do segmento sob a perspectiva sintática. $\mathrm{O}$ argumento floral preenche a função de adjunto adnominal. Essa interpretação do argumento é baseada em dois critérios:

a) o argumento se relaciona com uma base ativa ou deverbal ${ }^{7}$;

b) o argumento possui categoria gramatical adjetiva.

O satélite in vitro é um complemento circunstancial. Reservamos essa função a todos os componentes de uma UTC cuja categoria é uma locução adverbial.

Em se tratando das funções pragmáticas, indução é interpretada como o tópico, pois é o elemento ao qual todos os argumentos e satélites fazem referência a fim de precisar o objetivo de comunicação. Floral e in vitro são ditos focos, por serem elementos

${ }^{7}$ Base nominal derivada de verbo.

Inf. Inf., Londrina, v. 16 . n. 3. p. $25-51$, jan./ jun. 2011 
que especificam o estatuto informacional do elemento tópico, ou seja, ele pontua a informação do tópico.

A interpretação de cunho lingüístico-funcional aqui apresentada tem interesse principalmente em pesquisas orientadas a modelização de conhecimento lingüístico desenvolvidas em ambientes de inteligência artificial, ao desenvolvimento de sistemas de organização do conhecimento, a aplicação de análise facetada em estudos classificatórios, a elaboração de definição terminológica, a construção de softwares de extração terminológica entre outras. Alguns desses experimentos encontram-se registrados em Café (1999, 2000, 2006), Café, Mendes (2008) e Café, Mendes (2009).

\section{CONSIDERAÇÕES FINAIS}

O estudo dos aspectos semânticos envolvidos na organização do conhecimento devem pautar-se em teorias semânticas que forneçam o referencial teórico e metodológico capaz de orientar a análise conceitual. Tanto a representação da informação quanto a representação do conhecimento (BRÄSCHER; CAFÉ, 2010) partem da análise conceitual para chegar a um modelo de representação útil para efeitos de recuperação da informação.

Representar domínios do conhecimento exige modelos teóricos que dêem conta da realidade que se deseja modelar. Os desafios do processamento automático de textos impostos pelas demandas de recuperação inteligente da informação levam a modelos de representação cada vez mais complexos. Nesse contexto, algumas teorias oriundas da lingüística podem contribuir para a estruturação de referencial teórico e metodológico que sirva de base para a análise e representação de conceitos e seus relacionamentos.

A Teoria de Valência e a Gramática de Casos ofereceram as bases para a proposta dos Gráficos Conceituais de Sowa. Por ser uma proposta orientada para o processamento automático da linguagem natural, pode ser útil como modelo de representação conceitual para sistemas de organização do conhecimento aplicáveis à recuperação inteligente da informação.

A Teoria da Gramática Funcional por sua vez oferece uma base metodológica consistente não apenas para interpretar as expressões lingüísticas como também para sintetizar a análise via o modelo de predicação. Este modelo, representado pela regra de formação, organiza a informação veiculada pela expressão lingüística fornecendo assim o meio para automatizar o estudo da língua seja geral ou especializada. Sua utilidade pode ser verificada em sistemas voltados a modelagem de conhecimento lingüístico que para a 
área da Ciência da Informação moderna são fundamentais para a eficiência da recuperação da informação.

As teorias apresentadas têm por base uma abordagem sintático-semântica da linguagem, a qual julgou apresentar potencial de aplicação para a Ciência da Informação, diante da necessidade de tratamento automático de conteúdo textual para promover a melhoria dos sistemas de recuperação da informação.

Esperamos que as teorias aqui apresentadas viessem contribuir para o aprofundamento dos estudos voltados aos diversos fenômenos da área de organização do conhecimento e possam orientar a Ciência da Informação para um amadurecimento ainda maior.

\section{REFERÊNCIAS}

BLISS, H. E. A bibliographic classification. 2. ed. New York: H.W. Wilson, 1952.

BORBA, F. S. Uma gramática de valências para o português. São Paulo: Ática, 1996. $199 p$.

BRÄSCHER, M. A A ambuiguidade na recuperação da informação. Datagramazero, v.3, n. 1, 2002. Disponível em: < http://www.dgz.org.br/fev02/F_I_art.htm>. Acesso em 12 de agosto de 2011.

BRÄSCHER, M. Tratamento automático de ambigüidades na recuperação da informação. 290 f. Tese (Doutorado em Ciência da Informação) - Curso de Pós-graduação em Ciência da Informação, Universidade de Brasília, Brasília, 1999.

BRÄSCHER, Marisa; CAFÉ, Lígia. Organização da informação ou organização do conhecimento? In: LARA, Marilda L.G.; SMIT, Johanna. (Org.). Temas de pesquisa em Ciência da Informação no Brasil. São Paulo: Escola de Comunicação e Artes/USP, 2010. ISBN: 978-85-7205-081-4

CAFÉ, L. La description et l'analyse des unités terminologiques complexes en langue portugaise (variété brésilienne): une contribution à l'automatisation de la Banque de données terminologiques du Brésil (Brasilterm). 1999. 2 v. Tese (Doutorado em Lingüística) - Département de Langues et Linguistique, Université Laval, Québec, Canadá, 1999.

CAFÉ, L. Análise da formação de unidades terminológicas complexas (UTCs) sob a perspectiva da Gramática Funcional de Simon Dik: pistas de cunho lingüístico-funcional para o processamento da linguagem natural. In: SIMPÓSIO IBERO-AMERICANO DE TERMINOLOGIA, 6., 2000, Lisboa, Portugal. Anais. Lisboa, Portugal: União Latina, 2000.

CAFÉ, L. Aplicação do modelo de predicação sintático-semântica na construção de linguagens documentárias facetadas. In: CUNHA, M. V.; SOUZA, F. C.(Orgs.). 
Comunicação, Gestão e Profissão: abordagens para o estudo da ciência da informação. Belo Horizonte: Autêntica, 2006. p. 69-92.

CAFÉ, L. MENDES, Uma contribuição para a construção de instrumentos analíticosintéticos de representação do conhecimento. Perspectivas em Ciência da Informação, v. 13, p. 40-59, 2008.

CAFÉ, L. MENDES, F. Estudo sobre a estrutura definitória para desenvolvimento de ontologias. Informação \& sociedade. Estudos, v. 19, p. 71-80, 2009.

DAVIDSE, Kristin. M. A. K. Halliday's Functional Grammar and the Prague School. In: DIRVEN, René; FRIED Vilém (Org.) Functionalism in Linguistics. Amsterdam, Philadelphia: John Benjamins, 1987. p. 39-79. (Linguistics \& Literary Studies in Eastern Europe, 20).

DIK, S. Functional Grammar. Amsterdan: North-Holland, 1978. 230 p. (North-Holland Linguistics Series, 37).

DIK, S. Studies in Functional Grammar. London: Academic Press, 1980. 245 p.

DIK, Simon. Predication and Expression: the Problem and the Theorical Framework. In: Bolkestein, A. Machtelt et al. (Org.) Predication and expression in Functional Grammar. London: Academic Press, 1981. p. 1-17.

DIK, Simon. (Ed.). Advances in Funcional Grammar. Dordrecht, Holanda: Foris Publications, 1983. 415 p. (Publications in Languages Sciences; 11).

DIK, Simon. Some Principles of Functional Grammar. In: DIRVEN, René; FRIED Vilém (Org.) Functionalism in Linguistics. Amsterdam, Philadelphia: John Benjamins, 1987. p. 81-100. (Linguistics \& Literary Studies in Eastern Europe, 20).

DIK, Simon. The Structure of the Cause. In:DIK, Simon. The theory of Functional Grammar.Dordrecht, Holanda: Foris Publications, 1989. parte 1, p. 1-433. (Functional Grammar; 9).

DUCROT, Oswald.; TODOROV, Tzvetan, 1972. Fonctionnalisme, In:DUCROT, O.; TODOROV, T. Dictionnaire encyclopédique des sciences du langage. Paris, Seuil, p. 4248, 1972.

HJORLAND, B. Semantic and Knowledge organization. ARIST, v.41, p. 367-405, 2007.

FILLMORE, C. J. The Case for Case". In: UNIVERSALS in Linguistic Theory. New York: Holt, Rinehart, and Winston, 1968. p. 1-88.

HODGE, G. Systems of Knowledge Organization for Digital Libraries: beyond traditional authorities files. Washington, DC, the Council on Library and Information Resources. 2000. Disponível em: <http://www.clir.org/pubs/reports/pub91/contents.htm> Acesso em: 24 maio 2008.

KHOO, C. G.; NA, J-C. Semantic relations in information science. ARIST, v. 40, p. 157228, 2006.

LYONS, John. Language and Linguistics. Cambridge: Cambridge University Press, 1981. 
NEVES, Maria Helena de Moura. A gramática funcional. São Paulo: Martins Fontes, 1997.

SAGER, Juan C. A practical course in terminology processing. Amsterdam; Philadelphia: John Benjamin Publishing Company, 1990. 254p.

SOWA, J. F. Conceptual structures: information processing in mind and machine. Massachussetts: Addison-Wesley, 1984. 435p.

SOWA, J. F. Relating diagrams to Logic. In INTERNATIONAL CONFERENCE ON CONCEPTUAL STRUCTURES, ICCS'93, August 1993, Quebec City. Proceedings... p. 1-35. (Lectures Notes in Artificial Intelligence, 699).

TEIXEIRA, R.F.A. Fillmore: a relativização dos casos em cenas. In: NEVES, M. H. de M. Gramática de casos. Araraquara UNESP, 1987. P. 25-43.

TESNIÈRE, L. Eléments de syntaxique structurale. Paris: C. Klincksieck, 1959. 670p.

\title{
Title
}

Knowledge Organization: Semantic Theories As A Base For Concept Study And Representation

\begin{abstract}
This paper takes into consideration that knowledge organization involves semantic analysis and that Information Science needs a theoretical reference for studies that focus on the conceptual representation of knowledge domains. It presents methodological-theoretical alternatives rooted in Linguistics and that are based semantically on language studies: Valence Theory, Case Grammar, Conceptual Graphs and the Functional Grammar Theory. It prioritizes methodological-theoretical proposals based on the principle of interpretation of semantic problems that offer a way to consider and reflect on issues related to the different semantic aspects in the field of Knowledge Organization.
\end{abstract}

\section{Keywords}

Knowledge organization. Semantic theories. Conceptual analysis.

\section{Título}

Organización del conocimiento: Teorías Semánticas como base para estudios y representación de conceptos

\section{Resumen}

En este trabajo se considera que la organización del conocimiento involucra el análisis semántico y que las Ciencias de la Información necesitan de un marco de referencia teórico para los estudios que tienen por reto la representación conceptual de campos de conocimiento. Además, presenta alternativas teórico-metodológicas oriundas de la Lingüística y que parten de una base semántica del estudio de la lengua: Teoría de la Valencia, Gramática de Casos, Gráficos Conceptuales y Teoría de la Gramática Funcional. Prioriza las propuestas teórico-metodológicas que tengan como principio de interpretación los problemas semánticos y que ofrecen un camino para pensar y 
reflexionar sobre cuestiones relacionadas a los diferentes aspectos semánticos en el campo de la Organización del Conocimiento.

\section{Palabras clave}

Organización del conocimiento. Teorias semánticas. Análise conceptual.

Recebido em: 26/08/2011

Aceito em: 07/12/2011 